\title{
Erratum to: The impact of hip fracture on mortality in Estonia: a retrospective population-based cohort study
}

\author{
Mikk Jürisson ${ }^{1 *}$, Mait Raag ${ }^{1}$, Riina Kallikorm,3, Margus Lember ${ }^{2,3}$ and Anneli Uusküla ${ }^{1}$
}

\section{Erratum}

After the publication of the article [1] it came to our attention that the wrong versions of Figs. 1 and 3 were published. Please find below the correct version of Figs. 1 and 3.

\section{Author details \\ 'Institute of Family Medicine and Public Health, University of Tartu, Ravila st 19, 50411 Tartu, Estonia. ${ }^{2}$ Institute of Clinical Medicine, University of Tartu, L. Puusepa St 8, 51014 Tartu, Estonia. ${ }^{3}$ Internal Medicine Clinic, Tartu University Hospital, L. Puusepa St 8, 51014 Tartu, Estonia.}

Received: 17 August 2017 Accepted: 17 August 2017

Published online: 24 August 2017

\section{Reference}

1. Jürisson, et al. The impact of hip fracture on mortality in Estonia: a

retrospective population-based cohort study. BMC Musculoskelet Disord. 2017;18:243. doi:https://doi.org/10.1186/s12891-017-1606-1.

\footnotetext{
*Correspondence: mikkjurisson@gmail.com

1 Institute of Family Medicine and Public Health, University of Tartu, Ravila st

19, 50411 Tartu, Estonia
} 


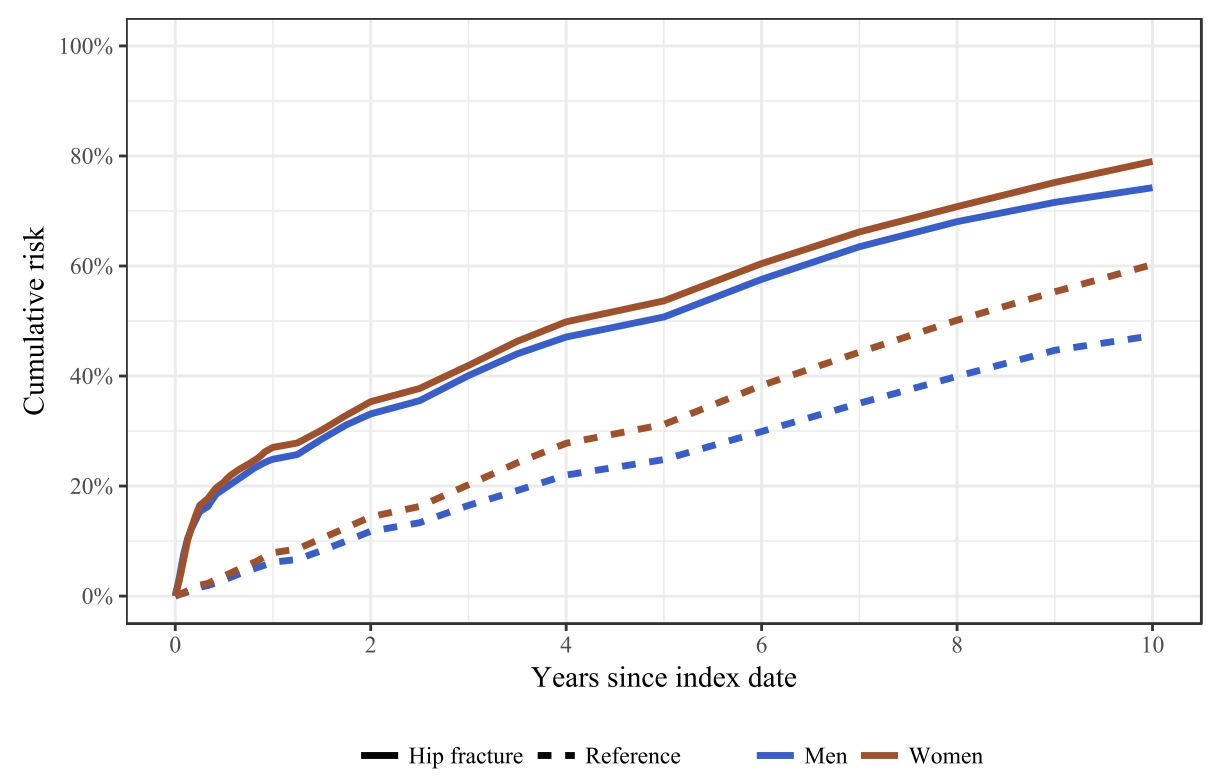

Fig. 1 Sex-specific cumulative 10-year risk of all-cause mortality (adjusted for age and Charlson index score) by study group in men and women $\geq 50$ years in Estonia, January 1, 2005-May 4, 2016

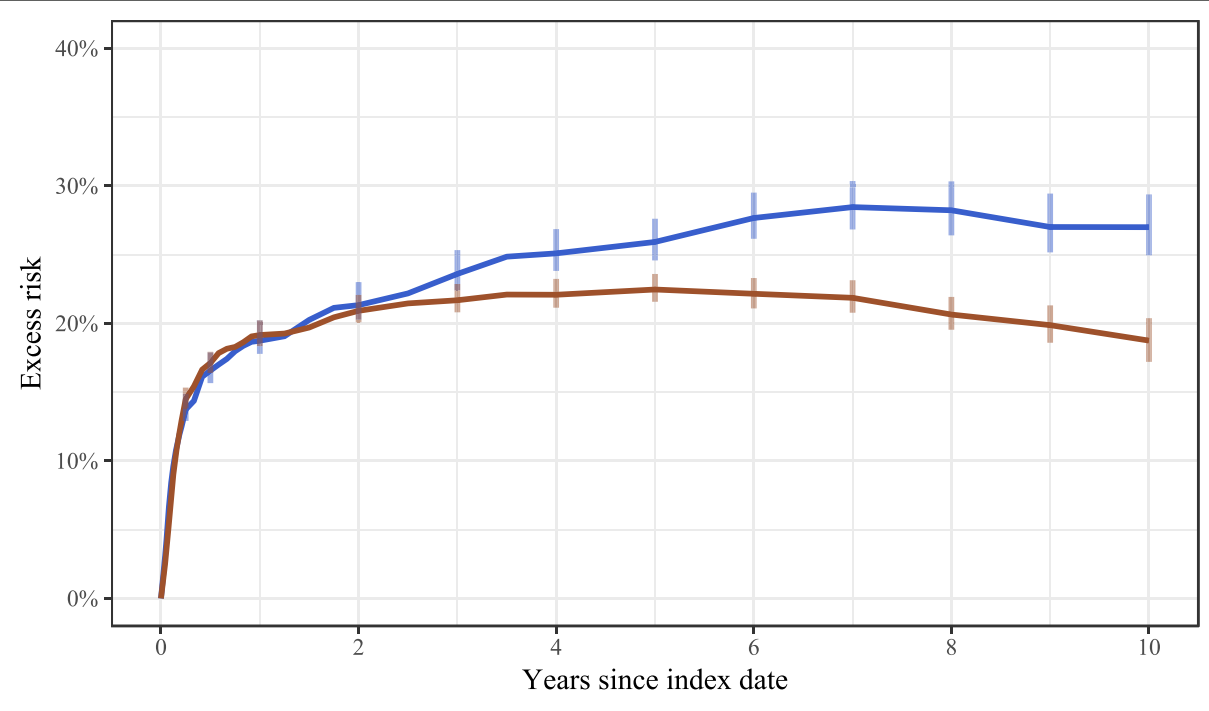

- Men - Women $\quad \mid 95 \% \mathrm{Cl}$

Fig. 3 Excess cumulative 10-year risk of all-cause mortality following hip fracture among men and women age $\geq 50$ years (adjusted for age and Charlson index score) in Estonia, January 1, 2005-May 4, 2016 